\title{
UMA NOVA CONFIGURAÇÃO DO TRABALHO: ANÁLISE INTERPRETATIVA DA LITERATURA DE COWORKING
}

\author{
A NEW WORKING CONFIGURATION: AN INTERPRETIVE \\ ANALYSIS OF THE COWORKING LITERATURE
}

\section{UNA NUEVA CONFIGURACIÓN DEL TRABAJO: ANÁLISIS INTERPRETATIVA DE LA LITERATURA DE COWORKING}

\author{
Breno Nakao \\ Mestrando em Administração da \\ Universidade do Sul de Santa Catarina, \\ Brasil \\ bnakao@gmail.com \\ Clarissa Carneiro Mussi \\ Doutora em Administração / Professora da \\ Univesidade do Sul de Santa Catarina, Brasil \\ mussi.clarissa@gmail.com
}

\author{
Contextus \\ ISSNe 2178-9258 \\ Organização: Comitê Científico Interinstitucional \\ Editor Científico: Diego de Queiroz Machado \\ Editor Executivo: Carlos Daniel Andrade \\ Avaliação: double blind review pelo SEER/OJS \\ Recebido em 15/08/2017 \\ Aceito em 19/04/2018 \\ $2^{\text {a }}$ versão aceita em 08/05/2018
}

\section{RESUMO}

Este estudo buscou compreender o escopo teórico do conceito de coworking. Foram realizadas uma revisão sistemática da literatura e uma análise interpretativa do conteúdo dos artigos identificados. Incluem-se entre as conclusões da pesquisa que: (a) o coworking é um conceito recente e pouco explorado; (b) ele tem sido explorado em diferentes níveis de análise: como componente de cidades ou culturas criativas, como pertencendo ao consumo colaborativo, como um entre diversos espaços de trabalho compartilhados e como elemento divergente de modelos tradicionais de trabalho; (c) há divergências de expectativas e demandas sobre o significado e a forma de uso de espaços de coworking; (d) os benefícios esperados do fenômeno não são observados em todos os espaços; (e) a construção colaborativa de significados e a formação de um senso comunitário são elementos importantes para o surgimento dos benefícios de coworking.

Palavras-chave: coworking; colaboração; inovação; trabalho; empreendedorismo.

\section{ABSTRACT}

This study sought to understand the theoretical scope of the concept of coworking. A systematic review of the literature and an interpretative analysis of the content of the identified articles were carried out. The conclusions of the research include: (a) coworking is a recent, not sufficiently explored concept; (b) it has been explored at different levels of analysis: as a component of creative cities or cultures, as belonging to collaborative consumption, as one among several shared workspaces and as working model divergent from traditional ones; (c) there are divergences of expectations and demands on the meaning and on the form of using coworking spaces; (d) the expected benefits of the phenomenon are not observed in all coworking spaces; (e) the collaborative construction of meanings and the formation of a community sense are important elements to the emergence of coworking benefits.

Keywords: coworking; collaboration; innovation; work; entrepreneurship.

\section{RESUMEN}

Esta investigación buscó comprender el alcance teórico del concepto de coworking. Se realizó una investigación de revisión sistemática de la literatura y el análisis interpretativo del contenido de los artículos identificados. Entre las conclusiones de la investigación, están que (a) el coworking es un concepto reciente y poco explorado; (b) él ha sido explorado en diferentes niveles de análisis: como componente de ciudades o culturas creativas, como perteneciente al consumo colaborativo, como uno entre diversos espacios de trabajo compartidos y como elemento de comparación con modelos tradicionales de trabajo; (c) hay divergencias de expectativas y demandas sobre el significado y la forma de uso de espacios de coworking; (d) los beneficios esperados del fenómeno no se observan en todos los espacios; (e) la construcción colaborativa de significados y la formación de un sentido comunitario son elementos importantes para el surgimiento de los beneficios de coworking. 
Palabras clave: coworking; colaboración; innovación; trabajo; emprendedor.

\section{INTRODUÇÃO}

Os espaços de coworking se proliferaram no mundo devido ao caráter de novidade do conceito e à crise econômica mundial (GANDINI, 2015). Diante dessa expansão, a produção acadêmica sobre o fenômeno torna-se pequena, sendo um indício o fato de trabalhos recentes ainda se concentrarem em descrições ou definições (CAPDEVILA, 2013; GANDINI, 2015; UDA, 2013). O termo coworking refere-se a espaços de trabalho compartilhados por diversos atores e/ou organizações, tais como autônomos, empreendedores, organizações sem fins lucrativos, bem como micro- e pequenas empresas (GANDINI, 2015; UDA, 2013). Tais espaços oferecem estruturas, suporte, conhecimentos e relacionamentos que podem não ser acessíveis em um espaço tradicional de trabalho (CAPDEVILA, 2013).

Para Spinuzzi (2012), os espaços de coworking são ambientes complexos, compostos por uma grande variedade de atores, com intenções e expectativas diversas. Isso frequentemente se evidencia de modo especial ao se compararem os proprietários dos espaços com os prestadores de serviço. $\mathrm{O}$ contexto a que pertencem os espaços ajuda a moldar uma identidade própria para cada local e as expectativas dos grupos que usufruem do coworking. O real valor do serviço para aqueles que ali trabalham, segundo a pesquisa de Spinuzzi (2012), pode ser mais abstrato e intangível, como benefícios da socialização, dada a presença de pares ou pessoas com o mesmo espírito de trabalho. Também se destacam: a segurança em torno dos pertences pessoais ou intelectuais, a localização e a possibilidade de aparentar profissionalismo em encontros com clientes - características em que um profissional autônomo ou pequeno negócio nem sempre é capaz de investir nem dos quais usufruir em espaços públicos ou no home office.

Também se discutem na literatura os efeitos positivos que características presentes em espaços de coworking - como o compartilhamento do espaço de trabalho e a riqueza de contatos - podem ter sobre o desempenho da criatividade, inovação e produtividade de indivíduos e equipes (LIEBOWITZ; BECKMAN, 1998; MAZNEVSKI; ATHANASSIOU, 2007; NONAKA; TAKEUCHI, 1997). Devido ao seu potencial de aproximar pequenos negócios, empreendedores e autônomos, há indícios de que aquele ambiente podem representar um importante fator de incentivo à inovação de uma região (CAPDEVILA, 2015). 
A crise econômica internacional de 2008 é citada como um fator que aumentou a demanda por espaços de coworking em Barcelona (CAPDEVILA, 2015). De forma semelhante, no Brasil, um período de baixo crescimento econômico e alta taxa de desemprego coincide com a expansão do fenômeno. O censo do coworking de 2015 apontou a existência de 238 espaços, enquanto o estudo de 2017 identificou 810 espaços (COWORKING BRASIL, 2017). Atualmente, o censo internacional estima que 1,27 milhão de pessoas utilizam espaços de coworking e projeta que, ao final de 2018, o número será de 1,69 milhão de usuários (DESKMAG, 2018). Esse aumento baseia-se em fatores como a tendência crescente de corporações que alocam parte de sua força de trabalho naqueles espaços para reduzir custos (DESKMAG, 2018).

Ainda há poucos trabalhos publicados sobre coworking, especialmente no Brasil. Para Uda (2013), a quantidade internacional de explorações teóricas sobre o fenômeno ainda é insuficiente. Isso pôde ser constatado durante a realização desta pesquisa, quando se observou que havia apenas uma revisão literária sobre o tema. Adicionalmente, Dos Santos (2014) e Maurer et al. (2015) apontam a cultura e a identidade cultural como fatores relevantes ao sucesso de fenômenos de consumo colaborativo, do qual o coworking faz parte. Segundo os mesmos autores, a maioria das discussões teóricas sobre o tema parte do contexto europeu ou norte-americano e não considera as particularidades do contexto socioeconômico brasileiro.

A lacuna de pesquisas sobre coworking, em conjunto com a rápida proliferação internacional e nacionalmente dessa prática, motivou a realização desta pesquisa. Seu objetivo é, por meio de uma revisão sistemática da literatura, compreender o escopo teórico do conceito e, com isso, mapear as diferentes percepções sobre ele.

Este trabalho está estruturado em quatro seções. A próxima descreve a metodologia utilizada para a consecução da pesquisa. A terceira seção apresenta os principais temas das publicações identificadas e reflete sobre o diálogo entre seus conteúdos. Ao final, são apresentadas as conclusões e sugestões de pesquisas futuras sobre o fenômeno de coworking. 


\section{METODOLOGIA}

A pesquisa possui caráter qualitativo (STRAUSS; CORBIN, 1998) e descritivo (GODOY, 1995). Utilizou um método estruturado de pesquisa em bases de dados eletrônicas (GERBER et al., 2013) visando identificar escritos sobre o tema. O método consiste em um processo sequencial de refinamento dos parâmetros de pesquisa até atingir uma base de trabalhos de acordo com os parâmetros especificados. O método possui as seguintes etapas (GERBER et al., 2013, p. 168): (a) parâmetros gerais da pesquisa; (b) recursos de apoio; (c) índices de busca; (d) refinamento preliminar; (e) refinamento avançado; (f) refinamento específico de títulos e resumos; ( $\mathrm{g}$ ) refinamento específico de textos completos; (h) base de trabalhos científicos.

Os parâmetros gerais da pesquisa, da etapa (a), consistem nos objetivos dela e no local de busca. Os objetivos da pesquisa foram mencionados na seção de introdução deste artigo. Como local de busca, foram selecionadas as bases de dados internacionais Web of Science, Scopus, Science Direct, Ebsco, ProQuest e as bases nacionais Scielo e Spell.

A etapa (b), voltada a recursos de apoio, decide sobre a utilização de recursos adicionais para a execução da pesquisa ou a organização dos resultados. Esta pesquisa utilizou o software Endnote para auxiliar no gerenciamento das referências bibliográficas identificadas. Ele permitiu agregar os resultados de buscas em diferentes bases de dados, ajudou a excluir trabalhos duplicados - aqueles encontrados em múltiplas bases de dados - e facilitou a etapa (f), a seleção de trabalhos a partir da leitura dos títulos e resumos, ao possibilitar a classificação dos trabalhos em "lidos", "não lidos” e em diferentes graus de relevância.

Em seguida, foram definidos os índices de busca, etapa (c), e refinamento preliminar dos termos de busca, etapa (d), que consiste em otimizar os resultados de pesquisa com as ferramentas de cada base de dados. Para iniciar a pesquisa, fez-se uma busca utilizando apenas o termo coworking. Os resultados desta etapa foram avaliados para aumentar a compreensão sobre o tema de pesquisa e refinar os termos de busca. A leitura preliminar de trabalhos encontrados, identificou que o termo co-working, com hífen, era também utilizado, e este foi adicionado aos índices de busca. Gerber et al. (2013, p. 168) também citam o uso de operadores booleanos e asteriscos para completar palavras aleatoriamente, por exemplo cowork*. Esta etapa revelou que o uso de * não produzia resultados próximos ao tema de pesquisa. Foi utilizado o operador booleano "OR", portanto, o termo de busca completo foi "coworking” OR "co-working". 
A etapa (e), refinamento avançado, adiciona novos critérios à busca como áreas de conhecimento, idioma, delimitação temporal e origem do trabalho (congresso, publicação revisada por pares, dentre outros). Essa etapa se iniciou acrescentando, à pesquisa booleana, a restrição de busca no título ou no resumo ou nas palavras-chave do artigo, obtendo-se 1.169 resultados. As bases de dados contêm publicações de diversas áreas do conhecimento, por isso a busca foi direcionada às áreas de gestão e negócios, economia e ciências sociais. Por exemplo, na plataforma Science Direct, a pesquisa restringiu-se às áreas de "Business, Management and Accounting", "Economics, Econometrics and Finance" e "Social Sciences". Esse tipo de restrição foi aplicado às bases Science Direct, Scopus, ProQuest e Ebsco. Dos resultados alcançados, foram filtrados os artigos acadêmicos publicados em periódicos revisados por pares ou apresentados em conferências, no período de 2000 a 2016, e nos idiomas inglês ou português, sendo encontrados 156 resultados. Após a eliminação de trabalhos duplicados, obtiveram-se 125 resultados. As bases de dados nacionais, Scielo e Spell, e a internacional Ebsco não apresentaram trabalhos com os termos da pesquisa.

Dados a não identificação de artigos nacionais sobre o tema e o baixo número de artigos encontrados nas bases de periódicos científicos, foram realizadas pesquisas adicionais no metabuscador Google Acadêmico e na plataforma de publicação de artigos em estágio inicial Social Science Research Network (SSRN). A pesquisa no Google Acadêmico, limitada a resultados em língua portuguesa, no mesmo período de 2000 a 2016, identificou 521 resultados. A pesquisa na plataforma SSRN, restrita ao mesmo período e com resultados em inglês, identificou 15 trabalhos. Ao total, 661 trabalhos foram avaliados na etapa seguinte.

Na etapa (f), eliminaram-se os trabalhos não pertinentes ao tema da pesquisa, por meio da leitura de títulos e resumos. Os resultados encontrados até essa etapa revelaram que o termo coworking apresenta, também, uma conotação diferente daquela que se desejou tratar nesta pesquisa. Por exemplo, foram encontrados artigos da área de psicologia que tratam de um tipo de terapia em grupo denominada de coworking e trabalhos associados à engenharia que utilizam o termo para descrever a interação entre dois ou mais mecanismos, como em "coworking gears". Além destes, também foram eliminados trabalhos que utilizavam o termo com o significado de colegas de trabalho.

A etapa $(\mathrm{g})$, refinamento específico de textos completos, tem o mesmo propósito que a anterior e prosseguiu com a leitura integral dos artigos. Essa etapa identificou 24 resultados, que formam a etapa (h), base de trabalhos - o conjunto de trabalhos julgados relevantes para compreender o objeto de pesquisa. Os selecionados incluem dezesseis artigos publicados em 
periódicos científicos, cinco trabalhos em estágio inicial de desenvolvimento pertencentes à plataforma SSRN e três trabalhos apresentados em conferências. O Quadro 1 apresenta, em ordem cronológica, a base de trabalhos utilizada pela pesquisa.

Quadro 1 - Base de trabalhos sobre coworking

\begin{tabular}{|c|c|c|c|c|}
\hline \multicolumn{2}{|c|}{ Autores } & \multirow{2}{*}{$\begin{array}{l}\text { Título } \\
\text { Working alone together } \\
\text { coworking as emergent } \\
\text { collaborative activity }\end{array}$} & \multirow{2}{*}{$\begin{array}{l}\text { Origem } \\
\text { Journal of } \\
\text { Business and } \\
\text { Technical } \\
\text { Communication }\end{array}$} & \multirow{2}{*}{$\begin{array}{l}\text { Ano } \\
2012\end{array}$} \\
\hline 1. & SPINUZZI, Clay & & & \\
\hline $\begin{array}{l}2 . \\
\text { FOT }\end{array}$ & $\begin{array}{l}\text { BILANDZIC, Mark; } \\
\text { I, Marcus }\end{array}$ & $\begin{array}{l}\text { Libraries as coworking spaces: } \\
\text { Understanding user } \\
\text { motivations and perceived } \\
\text { barriers to social learning }\end{array}$ & $\begin{array}{l}\text { Library Hi } \\
\text { Tech }\end{array}$ & 2013 \\
\hline 3. & CAPDEVILA, Ignasi & $\begin{array}{l}\text { Typologies of localized spaces } \\
\text { of collaborative innovation }\end{array}$ & SSRN & 2013 \\
\hline 4. & LEUNG, Zeno CS & $\begin{array}{l}\text { Boundary spanning in } \\
\text { interorganizational } \\
\text { collaboration }\end{array}$ & $\begin{array}{l}\text { Administration } \\
\text { in Social Work }\end{array}$ & 2013 \\
\hline 5. & UDA, Tadashi & $\begin{array}{l}\text { What is Coworking?: A } \\
\text { Theoretical Study on the } \\
\text { Concept of Coworking }\end{array}$ & SSRN & 2013 \\
\hline 6. & CAPDEVILA, Ignasi & $\begin{array}{l}\text { Different Inter-Organizational } \\
\text { Collaboration Approaches in } \\
\text { Coworking Spaces in } \\
\text { Barcelona }\end{array}$ & SSRN & 2014 \\
\hline 7. & CAPDEVILA, Ignasi. & $\begin{array}{l}\text { Co-working spaces and the } \\
\text { localised dynamics of } \\
\text { innovation in Barcelona }\end{array}$ & $\begin{array}{l}\text { International } \\
\text { Journal of } \\
\text { Innovation } \\
\text { Management }\end{array}$ & 2015 \\
\hline $\begin{array}{l}8 . \\
\text { MU }\end{array}$ & $\begin{array}{l}\text { CARVALHAL, Felipe; } \\
\text { ZIO, Henrique }\end{array}$ & $\begin{array}{l}\text { ECONOMIA CRIATIVA E } \\
\text { LIDERANÇA CRIATIVA: } \\
\text { UMA ASSOCIAÇÃO (IM) } \\
\text { POSSÍVEL? }\end{array}$ & $\begin{array}{l}\text { Revista } \\
\text { Eletrônica de } \\
\text { Administração } \\
\text { (Porto Alegre } \\
\text { Online) }\end{array}$ & 2015 \\
\hline 9. & FUZI, Anita & $\begin{array}{l}\text { Co-working spaces for } \\
\text { promoting entrepreneurship in } \\
\text { sparse regions: the case of } \\
\text { South Wales }\end{array}$ & $\begin{array}{l}\text { Regional } \\
\text { Studies, } \\
\text { Regional } \\
\text { Science }\end{array}$ & 2015 \\
\hline 10. & GANDINI, Alessandro & $\begin{array}{l}\text { The rise of coworking spaces: } \\
\text { A literature review }\end{array}$ & Ephemera & 2015 \\
\hline 11. & JYLHÄ, Tuuli & $\begin{array}{l}\text { Towards business potential of } \\
\text { workplace services in Finland }\end{array}$ & $\begin{array}{l}\text { Procedia } \\
\text { Economics and } \\
\text { Finance }\end{array}$ & 2015 \\
\hline
\end{tabular}


(CONTINUAÇÃO)

Henrique Strapasson;
12. MAURER, Angela Maria et al.

13. MILECK, Luiz PADOVANI, Stephania

14. PARRINO, Lucia
Yes, we also can! O

desenvolvimento de iniciativas

de consumo colaborativo no

Brasil

Cocriação no mercado: um

estudo exploratório de

processos criativos de

empreendedores

Coworking: assessing the role of proximity in knowledge exchange

15. ROHDEN, Simoni
Fernanda et al.
16. SCHOPFEL, Joachim;
ROCHE, Julien; HUBERT,
Gilles

Consumo Colaborativo:

Economia, Modismo ou

Revolução?
Co-working and innovation:

new concepts for academic

libraries and learning centres
Revista de

administração e

contabilidade

2015

da Unisinos

SSRN

2015

Knowledge

Management

Research \&

2015

Practice

Desenvolve

Revista de

Gestão do

Unilasalle

New Library

World

2015

International

Conference on

Sharing Workspace, Sharing

17. SOERJOATMODJO,

Gita Widya Laksmini, et al.

Knowledge: Knowledge

Sharing Amongst

Intellectual

Capital and

Knowledge

2015

Entrepreneurs in Jakarta Co-

Working Spaces

Management

and

Organisational

Learning

18. DOS SANTOS, Claudia Coworking: contribuições de

Maria Neme

um modelo de consumo

colaborativo e da arquitetura

corporativa para o

Revista

2014

Nacional de

Gerenciamento

de Cidades

gerenciamento das cidades

$\begin{aligned} \text { 19. KUBÁTOVÁ, Jaroslava } & \begin{array}{l}\text { The Cause and Impact of the } \\ \text { Development of Coworking in } \\ \text { the Current Knowledge } \\ \text { Economy }\end{array}\end{aligned}$

20. ASSENZA, Pauline If You Build It Will They

Come? The Influence of

Spatial Configuration on Social

and Cognitive Functioning and

European

2014

Conference on

Knowledge

Management

Journal of

Management

2015

Policy and

Practice

Knowledge Spillover in

Entrepreneurial Co-Working

and Hacker Spaces 


\section{(CONTINUAÇÃO)}

\begin{tabular}{|c|c|c|c|}
\hline $\begin{array}{l}\text { 21. ŠVIRÁKOVÁ, E., } \\
\text { SOUKALOVÁ, R., BEDNÁR, } \\
\text { P., \& DANKO, L }\end{array}$ & $\begin{array}{l}\text { Culture managers education: } \\
\text { system dynamics model of the } \\
\text { coworking design centre }\end{array}$ & $\begin{array}{l}\text { Procedia-Social } \\
\text { and Behavioral } \\
\text { Sciences }\end{array}$ & 2015 \\
\hline 22. KOJO, Inka, et al. & $\begin{array}{l}\text { Typologies for co-working } \\
\text { spaces in Finland-what and } \\
\text { how? }\end{array}$ & Facilities & 2016 \\
\hline KUBÁTOVÁ, Jaroslava & $\begin{array}{l}\text { Cultural Differences in } \\
\text { Knowledge Sharing in Virtual } \\
\text { Environment }\end{array}$ & $\begin{array}{l}\text { European } \\
\text { Conference on } \\
\text { Knowledge } \\
\text { Management }\end{array}$ & 2016 \\
\hline $\begin{array}{l}\text { 24. POTTS, Jason; } \\
\text { WATERS-LYNCH, Julian M }\end{array}$ & $\begin{array}{l}\text { The Social Economy of } \\
\text { Coworking Spaces: A Focal } \\
\text { Point Model of Coordination }\end{array}$ & SSRN & 2016 \\
\hline
\end{tabular}

Fonte: elaborado pelos autores (2018).

Para compreender o escopo teórico do conceito de coworking, empregou-se o método de análise de conteúdo (BARDIN, 2009) no conjunto dos vinte e quatro trabalhos resultantes, mais especificamente a análise de conteúdo interpretativa (DRISKO; MASCHI, 2016). Foi utilizada a categorização aberta, ou seja, as categorias teóricas sobre coworking emergiram dos dados analisados (BARDIN, 2009; EISENHARDT, 1989; STRAUSS; CORBIN 1998,). Isso possibilitou identificar quatro categorias relacionadas ao coworking e elaborar um diálogo entre os conteúdos em torno delas. Na seção seguinte, são apresentadas as categorias emergentes: (1) origens e definições de coworking, (2) perspectivas de usuários (coworkers) e proprietários (hosts) em espaços de coworking, (3) a inovação do espaço de trabalho e (4) configurações de trabalho em espaços de coworking.

\section{APRESENTAÇÃO E ANÁLISE DOS DADOS}

Os trabalhos selecionados foram publicados em diversos periódicos e conferências, com uma maior representatividade daqueles realizados na União Europeia e nos Estados Unidos. Os temas principais explorados pelos periódicos e conferências incluem gestão do conhecimento, aprendizagem organizacional, gestão empresarial, gestão de serviços sociais, economia e finanças, tecnologia e inovação, estudo de bibliotecas, comportamento social, estudos regionais e estudo de políticas. Entre os trabalhos identificados, destacam-se:

- Spinuzzi (2012), com o trabalho mais influente, totalizando 146 citações;

- Gandini (2015), a única revisão literária; 
- Capdevila (2013; 2014; 2015), único autor com múltiplos trabalhos selecionados;

- Maurer et al. (2015), trabalho nacional com o maior número de citações (7).

Foram encontrados apenas cinco artigos nacionais e todos eles estudam o coworking como parte de outros fenômenos, como cocriação (MILECK; PADOVANI, 2015), economia criativa (CARVALHAL; MUZZIO, 2015), consumo colaborativo (DOS SANTOS, 2014; MAURER et al., 2015; ROHDEN et al., 2015), ou mesmo outras áreas do conhecimento, como a gestão urbana e arquitetura (DOS SANTOS, 2014).

Por meio da análise de conteúdo, emergiram quatro categorias presentes nos 24 artigos da base de trabalhos. O Quadro 2 reúne estas categorias e os autores que tratam de cada uma delas.

Quadro 2 - Categorias e autores dos trabalhos referentes a coworking

\begin{tabular}{|c|c|c|}
\hline Categoria & Autores Internacionais & Autores Nacionais \\
\hline $\begin{array}{l}\text { 1. Origens e } \\
\text { definições de } \\
\text { coworking }\end{array}$ & $\begin{array}{l}\text { Capdevila (2013, 2014, 2015); } \\
\text { Gandini (2015); Kojo et al. (2016); } \\
\text { Spinuzzi (2012); Uda (2012) }\end{array}$ & $\begin{array}{l}\text { Maurer et al. (2015); } \\
\text { Rohden et al. (2015); Dos } \\
\text { Santos (2014) }\end{array}$ \\
\hline $\begin{array}{l}2 . \quad \text { Perspectivas de } \\
\text { usuários (coworkers) e } \\
\text { proprietários (hosts) em } \\
\text { espaços de coworking }\end{array}$ & $\begin{array}{l}\text { Bilandzic e Foth (2013); Capdevila } \\
\text { (2015); Fuzi (2015); Kubátová } \\
(2014,2016) ; \text { Leung (2013); } \\
\text { Schopfel, Roche e Hubert (2015); } \\
\text { Spinuzzi (2012); Šviráková et al. } \\
\text { (2015) }\end{array}$ & $\begin{array}{l}\text { Carvalhal e Muzzio } \\
\text { (2015); Mileck e Padovani } \\
\text { (2015); Rohden et al. } \\
(2015)\end{array}$ \\
\hline $\begin{array}{l}\text { 3. A inovação do } \\
\text { espaço de trabalho }\end{array}$ & $\begin{array}{l}\text { Assenza (2015); Bilandzic e Foth } \\
\text { (2013); Capdevila (2014, 2015); Fuzi } \\
\text { (2015); Kubátová (2014, 2016); } \\
\text { Leung (2013); Parrino (2015); Potts } \\
\text { e Waters-Lynch (2016); Spinuzzi } \\
\text { (2012); Schopfel, Roche e Hubert } \\
\text { (2015); Soerjoatmodjo et al. (2015); } \\
\text { Šviráková et al. (2015); Uda (2012) }\end{array}$ & $\begin{array}{l}\text { Carvalhal e Muzzio } \\
\text { (2015); }\end{array}$ \\
\hline $\begin{array}{l}\text { 4. Configurações } \\
\text { de trabalho em espaços } \\
\text { de coworking }\end{array}$ & $\begin{array}{l}\text { Capdevila (2015); Gandini (2015); } \\
\text { Fuzi (2015); Jylhä et al. (2015); } \\
\text { Parrino (2015); Potts e Waters-Lynch } \\
\text { (2016); Schopfel, Roche e Hubert } \\
\text { (2015); Spinuzzi (2012); }\end{array}$ & \\
\hline
\end{tabular}

Fonte: elaborado pelos autores (2018).

A primeira categoria, apresentada na seção 3.1, é representada pelas origens e definições do termo coworking. O segundo tema, abordado na seção 3.2, trata das diferenças de perspectivas, objetivos e expectativas entre usuários dos espaços - os coworkers - e os proprietários e/ou gerentes responsáveis por estes espaços - os hosts. O terceiro tema, descrito 
na seção 3.3, discute como ocorre o trabalho nos espaços de coworking e quais as suas potencialidades. O quarto tema, apresentado na seção 3.4, aborda as configurações de trabalho em espaços de coworking.

\subsection{Origens e definições de coworking}

Apesar de frequentemente serem encontrados de forma intercambiável na literatura, há uma distinção entre coworking e co-working. (GANDINI, 2015). O termo co-working, com hífen, descreve o trabalho lado a lado em um mesmo projeto, enquanto coworking descreve o trabalho individual em um espaço compartilhado (GANDINI, 2015), que possui a opção de interação social (SPINUZZI, 2012). Spinuzzi (2012), ao entrevistar usuários sobre o significado de coworking, descobriu que não há uma definição concisa. A análise dos artigos selecionados pela pesquisa permitiu identificar que o conceito é explorado em quatro níveis de análise, do mais amplo ao mais específico:

1. Coworking como componente de cidades criativas ou cultura criativa (DOS SANTOS, 2014; GANDINI, 2015);

2. Coworking como pertencendo ao consumo colaborativo (MAURER et al., 2015) em conjunto com outras atividades de mercado;

3. Coworking como um entre diversos espaços de trabalho compartilhados (CAPDEVILA, 2013; SPINUZZI, 2012);

4. Coworking em comparação com modelos tradicionais de trabalho, como empreendedores de pequeno porte e trabalho autônomo (UDA, 2013).

O primeiro nível de análise identificado é o coworking como componente de uma cultura criativa ou cidades criativas. Segundo Gandini (2015), o coworking começou em São Francisco na região do Vale do Silício em 2005, onde a interseção de tecnologias, espaço e pessoas, originou conceitos como classe criativa (termo que se refere a uma classe econômica de empreendedores), cidades criativas ou inteligentes (utilizado quando o critério de categorização são regiões geográficas) e culturas criativas (usado quando o escopo da análise do padrão de comportamento inovador é no âmbito de nações ou populações).

Enquanto a cultura criativa e a vida socialmente ativa em cidades podem atrair profissionais criativos, para Capdevila (2015), o conceito de cidades criativas é apenas 
descritivo, não explicando como de fato ocorre o processo de inovação localizada devido à concentração de capital intelectual. Para Capdevila (2015), os agentes da mudança em cidades criativas são as comunidades locais e suas atividades, não a proximidade geográfica ou a concentração urbana. As comunidades fazem o papel de conector entre pequenos grupos de pessoas inovadoras e firmas de mercado, as quais levam as inovações de agentes locais aos consumidores finais (CAPDEVILA, 2015). Essa articulação pode ocorrer por meio de (a) lugares, como cafés, restaurantes, museus e espaços públicos; (b) eventos, como palestras, workshops, seminários; (c) projetos colaborativos; ou por meio de (d) espaços compartilhados, como ocorre em espaços de coworking (CAPDEVILA, 2015). A identificação do papel de comunidades para a economia, inovação e o desenvolvimento de cidades é relevante, pois como observou Capdevila (2013), as políticas públicas limitam-se aos níveis de firmas, com a oferta de benefícios fiscais, e no nível de indivíduos, com políticas para atrair talentos e capacitar a população. Poucas políticas promovem o desenvolvimento das comunidades, o intermediário entre estes dois grupos.

Pratt (2008) critica a formação de cidades criativas ao afirmar que, no mundo digital, a classe criativa e suas ideias possuem uma facilidade ainda maior de mobilidade e evasão do que na economia industrial. $\mathrm{O}$ autor enfatiza que foi precisamente esta evasão de indústrias multinacionais que originou a necessidade de se utilizar as cidades criativas como estratégia de desenvolvimento. Dessa forma, as cidades criativas seriam ainda mais vulneráveis à mesma evasão produtiva que condicionou sua criação. Para Pratt (2008), o simples acúmulo de pessoas criativas em uma região é insuficiente para oferecer mudanças econômicas estruturais duradouras.

O segundo nível de análise explora a semelhança do coworking com outras formas de consumo colaborativo. MAURER et al. (2015, p. 69) descrevem o consumo colaborativo como as pessoas "alugando, emprestando e compartilhando bens em vez de comprá-los". O coworking seria uma forma de consumir um mesmo espaço físico de trabalho, compartilhando seus custos e obtendo um valor maior do que as organizações seriam capazes de comprar individualmente. Dos Santos (2014, p. 85) destaca o potencial do fenômeno em fortalecer laços comunitários:

O consumo colaborativo constitui-se um movimento focalizado no conceito de compartilhamento, que ressalta o senso de comunidade e resgata práticas sociais cooperativas. Possibilita aquisições e o uso de bens, espaços e serviços de forma coletiva, como compras, 
locações, uso compartilhado de espaços de trabalho, de transporte e de transportes alternativos, dentre outras iniciativas inovadoras.

Maurer et al. (2015) concorda com Dos Santos (2014) a respeito da origem do consumo colaborativo, ambos veem o fenômeno como relacionado a formas comerciais empregadas pela humanidade antes da economia capitalista, que passa a valorizar a posse de mercadorias. Segundo os autores, o consumo colaborativo geralmente se inicia com o objetivo de criar economias de custo, promover a reunião de pessoas, por conveniência, ou por consciência sustentável e social.

Sob esta perspectiva, coworking é o consumo ou compartilhamento de um ambiente de trabalho por diversas pessoas (DOS SANTOS, 2014; MAURER et al., 2015; ROHDEN et al., 2015), e semelhante ao consumo colaborativo de outras atividades intangíveis, como o compartilhamento de veículos pessoais (Zimride, Caronetas), compartilhamento de hospedagem (couchsurfing), o esforço coletivo de financiamento de projetos (crowdfunding, como Kick Starter e Catarse) ou compartilhamento de ideias e soluções (crowdsourcing, como Designcrowd) (ROHDEN et al., 2015).

Maurer et al. (2015) apontam a confiança como um dos valores essenciais do consumo colaborativo, uma vez que ela é um condicionante para as atividades de colaboração e compartilhamento. Logo, para Maurer et al. (2015), o sucesso do fenômeno social e comunitário depende de fatores que podem estar no nível de indivíduos. Especificamente sobre a atividade de coworking como consumo colaborativo, Dos Santos (2014) observa que ele é procurado por pessoas que valorizam o uso sustentável de recursos, a redução de custos operacionais, para incrementar a produtividade, e por permitir a descentralização dos locais de trabalho viabilizando a prática de atividades remotas.

O terceiro nível de análise do conceito de coworking, encontrado nos artigos selecionados pela pesquisa, é a comparação do conceito com outros espaços colaborativos. Spinuzzi (2012) descreve o coworking como escritórios abertos que organizações e autônomos podem alugar, para compartilhar custos e facilitar o trabalho colaborativo. Para Capdevila (2013, p. 2, tradução nossa), o coworking pode ser classificado como um "espaço localizado de inovação colaborativa" e agrupado com outros espaços como Hackerspaces, Maker spaces e Fabrication Labs. Capdevila (2013) identifica três características comuns a estes tipos de espaços: 1) eles são abertos ao público, 2) possuem um foco e objetivos coletivos consentidos por seus integrantes e 3) há um encorajamento do compartilhamento livre de conhecimento, 
ferramentas e informações entre os integrantes. As três características podem, ou não, serem encontradas em espaços de coworking, mas para Capdevila (2015), as características (2) e (3), o foco em uma comunidade e o compartilhamento de recursos e conhecimentos, são o que diferencia o fenômeno de coworking de simplesmente escritórios compartilhados. Portanto, os espaços de coworking têm potencial para formação de redes interorganizacionais e para a ocorrência de cooperação, compartilhamento, cocriação de valor e/ou colaboração.

Os Hackerspaces e Maker spaces são espaços para entusiastas que oferecem acesso a máquinas e ferramentas e permitem a experimentação com diferentes tecnologias e processos produtivos. (CAPDEVILA, 2013). São espaços auto organizados, frequentemente como organizações sem fins lucrativos, abertos ao público, com foco na livre troca de conhecimentos e independentes entre si, com os Hacker spaces adotando valores da ética hacker como a descentralização. (CAPDEVILA, 2013). Os Fab Labs, ou Fabrication Labs, são uma rede de espaços que permitem acesso a tecnologias de prototipagem rápida, como impressoras 3D e máquinas de corte a laser, e a produção em pequena escala. (CAPDEVILA, 2013). O espaço é utilizado por jovens, inventores, empresas e estudantes para fins de ensino, desenvolvimento profissional e pesquisa aplicada. (CAPDEVILA, 2013). Todos os Fab Labs seguem a cartilha do MIT.

O coworking difere dos demais espaços por estar associado ao mercado na percepção de usuários de espaços compartilhados - uma vez que os espaços de coworking geralmente atraem startups ou autônomos que visam ao lucro (CAPDEVILA, 2013). Porém, também há espaços de coworking voltados a atividades sem fins lucrativos como a inovação social, com objetivos de engajar a população local na prática da cidadania, de integração social, de promover a economia sustentável e de auxiliar na criação de uma comunidade autônoma (CAPDEVILA, 2014; KOJO et al., 2016). Fuzi (2015), por exemplo, explora o potencial de coworking como uma alternativa para promover o empreendedorismo em áreas que oferecem pouco suporte ao empreendedorismo. Fuzi (2015) ressalta que nestas regiões o espaço de coworking oferece diversas funções de suporte (moral, emocional, profissional, financeiro) e de infraestrutura para permitir que empreendedores comecem e cresçam seus negócios, incorporando funções de aceleradoras ou incubadoras de acordo com as necessidades da comunidade local.

O quarto nível de análise encontrado entre os artigos selecionados é a comparação do coworking com as formas tradicionais de trabalho, como pequenos empreendedores, 
profissionais autônomos e funcionários de organizações. Em sua revisão literária, Gandini (2015, p. 195, tradução nossa) define o termo coworking como:

um intermediário entre a vida 'normal' de trabalho, dentro de um espaço tradicional, bem delineado, em um ambiente quase-comunitário, e a vida de trabalho independente como um autônomo, caracterizada pela liberdade e independência, onde o autônomo encontra-se isolado em sua casa.

A pesquisa de Uda (2013) também caracteriza o coworking como um híbrido com potencial para agregar as vantagens do trabalho autônomo e do trabalho organizacional em um mesmo ambiente (Figura 1).

Figura 1 - Formas de trabalho segundo grau de proximidade e abertura, bem como de interação e diversidade
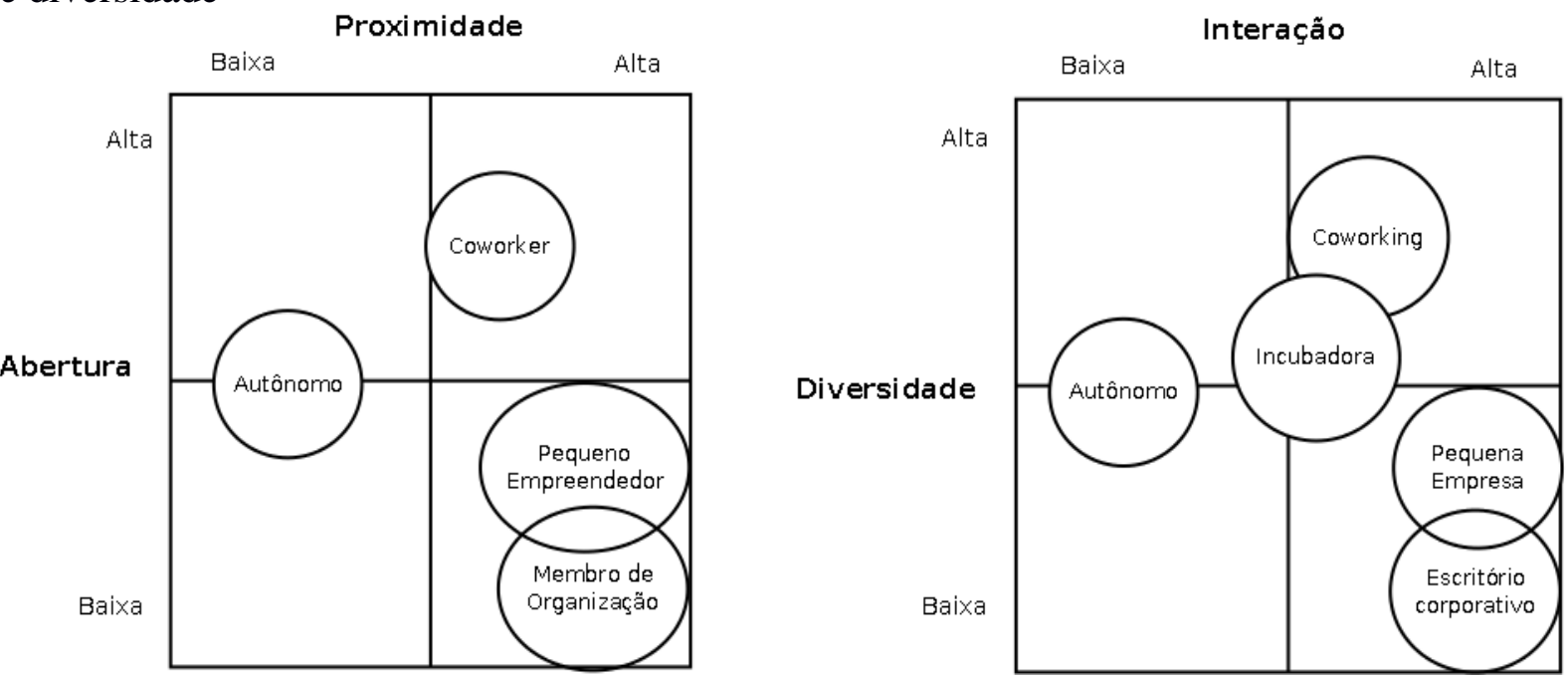

Fonte: adaptado de Uda (2013)

$\mathrm{O}$ autor define grau de proximidade entre indivíduos como a proximidade física entre seus espaços de trabalho. O grau abertura representa o quanto o local de trabalho está aberto a influências e pessoas externas. (UDA, 2013). No modelo à direita, o grau de interação qualifica o contato físico e a comunicação com outras pessoas. $\mathrm{O}$ grau de diversidade se refere à extensão da variedade de atributos presentes entre pessoas em um espaço de trabalho. O modelo permite constatar uma correspondência entre os graus de proximidade e interação e os graus de abertura e diversidade, apresentados na Figura 1. Quanto maior a proximidade física entre pessoas, ou suas estações de trabalho, maior o seu grau de interação com outras pessoas; e quanto maior o grau de abertura ao ambiente externo, maior a diversidade de atributos encontrados entre as pessoas que interagem no local de trabalho (UDA, 2013).

O modelo da Figura 1 ilustra que, nos modos tradicionais de trabalho, há trade-offs entre os benefícios associados à proximidade ou abertura, e entre os benefícios associados à interação 
ou diversidade; por exemplo, entre a autonomia do trabalho individual, também solitário, e a solidariedade do trabalho em organizações, mas que é possível devido as similaridades de seus empregados. O coworking possibilita superar estes trade-offs de duas formas: a) ao formarem espaços organizacionais bem delimitados, como as organizações tradicionais, porém com fronteiras e afiliações flexíveis, como é característico de profissionais autônomos que possuem redes de contatos ativas (GANDINI, 2015); b) quando coworkers não se restringem a um único trabalho, ocupação, organização (UDA, 2013), ou mesmo um único espaço de coworking (SPINUZZI, 2012). É dessa forma que o trabalho em espaços de coworking se apresenta como um híbrido: ao combinar os méritos do trabalho individual, como a diversidade de contatos, autonomia, independência e liberdade sobre as condições de trabalho, com os méritos do trabalho organizacional - como a solidariedade, interatividade e proximidade de pessoas (GANDINI, 2015; UDA, 2013).

Uda (2013) reforça que suas caracterizações (Figura 1) são teóricas, utilizadas para descrever um coworking típico que simplifica o fenômeno real, sendo natural haver exceções tanto em coworking como nos outros modelos de trabalho utilizados em comparações. $\mathrm{O}$ autor ainda realça que ao reportar suas experiências de coworking, usuários tendem a enfatizar os aspectos positivos do fenômeno, criando um viés que pode omitir aspectos negativos do coworking. Segundo Kojo et al. (2016), as diferentes perspectivas de coworking indicam que ainda não há uma definição precisa para o coworking, há apenas percepções subjetivas sobre o que é um espaço de coworking. Mesmo assim, usuários são capazes de distinguir funções e propósitos para os diversos modos de espaços compartilhados, com espaços diferentes, atraindo públicos diferentes e por motivos diferentes (KOJO et al., 2016). A Figura 2 apresenta um esquema conceitual que reúne os quatro níveis de análise (do mais amplo ao mais específico) pelos quais o conceito de coworking é explorado nos artigos utilizados por esta pesquisa. 
Figura 2 - Níveis de análise utilizados para conceituar o coworking

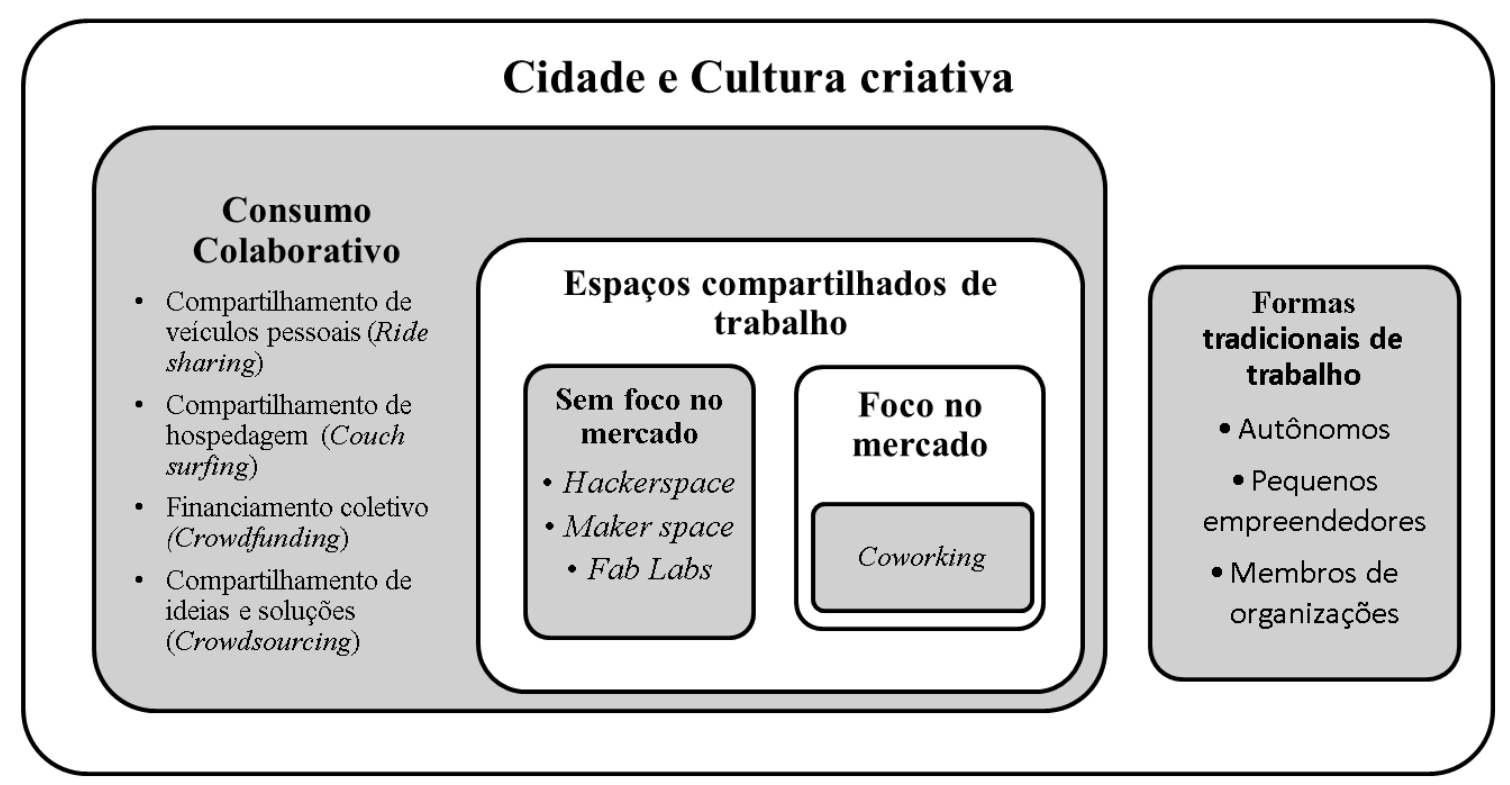

Fonte: elaborado pelos autores (2018).

O primeiro nível de análise, explorado por autores como Gandini (2015) e Capdevila (2015), é o de cidades e cultura criativa, o conceito mais amplo que inclui os espaços de coworking. O segundo nível é o consumo colaborativo, que está inserido no contexto de cidade criativa. É abordado por Maurer et al. (2015), Rohden et al. (2015) e Dos Santos (2014) e segundo os autores, o coworking é um tipo de consumo colaborativo, entre vários. O terceiro nível de análise são os espaços compartilhados de trabalho, composto por espaços compartilhados de trabalho sem foco no mercado - destinados a atividades sem fins lucrativos, aprendizagem e hobbys - e espaços compartilhados de trabalho com foco em mercado, no qual está incluído o coworking. O quarto e mais específico nível é o de espaços com foco em mercado, que compara o coworking e as formas tradicionais de trabalho, como empreendedores e autônomos (UDA, 2013). Entretanto, estas categorias são teóricas e, frequentemente, as diferenças entre espaços não são claras. É possível que dentro de certas condições, o coworking pode ser funcionalmente indistinguível de um home office ou um escritório tradicional. É possível também que duas empresas possuam experiências de trabalho distintas dentro de um mesmo espaço. Ao explorar o fenômeno sob diferentes perspectivas, é possível uma compreensão mais holística do fenômeno que auxilia a reconhecer o potencial do coworking em servir a um nicho específico de usuários e que não é atendido por outros tipos de espaço de trabalho. 


\subsection{Perspectivas de usuários (coworkers) e proprietários (hosts) em espaços de coworking}

Pode ser necessário conciliar interesses, expectativas e perspectivas divergentes em um mesmo espaço de coworking, sejam eles entre grupos de usuários ou entre usuários e proprietários (SPINUZZI, 2012). Um profissional autônomo que precisa de um ambiente profissional para se encontrar com clientes tem necessidades e expectativas diferentes de um ator que procura expandir sua rede de contatos profissionais e obter contratos de serviço (SPINUZZI, 2012).

Devido à novidade do fenômeno coworking, diversos estudos buscam mapear estes interesses, expectativas e motivações de coworkers e outros usuários de espaços compartilhados. As entrevistas e conversas informais de Bilandzic e Foth (2013) com usuários do espaço "The Edge" - uma biblioteca com design voltado à socialização que pode ser utilizada para coworking - apontaram possíveis motivos para o uso de espaços de trabalho compartilhados: 1) acesso gratuito a recursos, computadores, Internet, equipamento de multimídia; 2) ambiente de aprendizado informal, com workshops, palestras, exibições e eventos similares; 3) um espaço sem as distrações da vida doméstica e as pressões do trabalho que permita trabalhar ao lado (co-working) de outros indivíduos e grupos. Entre as características valorizadas por usuários, Spinuzzi (2012) cita a conveniência, boa localização, baixo custo, maior flexibilidade e pouco compromisso financeiro quando comparado com a locação de um escritório próprio, e menos distrações do que o trabalho em home office. A pesquisa de Kubátová (2014) identificou que a busca pelo serviço faz parte de uma mudança no comportamento da força de trabalho. Segundo o autor, há uma tendência de aumento no trabalho autônomo e individual, que considera o modelo de trabalho tradicional restritivo. $\mathrm{O}$ coworking, segundo o autor, é uma forma de atender a essa demanda por maior liberdade, autonomia, flexibilidade, segurança no emprego e satisfação no trabalho.

Para serem efetivos, os espaços devem ser projetados de forma que suas escolhas estratégicas estejam refletidas em aspectos como valores, ambiente, propósito, regras, políticas de uso do espaço, entre outros. Espaços projetados para incentivar a socialização, como a biblioteca "The Edge", têm como um dos seus atrativos a possibilidade de conhecer pessoas e ter conversas casuais. Este único objetivo, pode ser desdobrado em diversas decisões estratégicas. Este espaço projetado para a socialização no espaço de trabalho deve promover valores como abertura, flexibilidade, facilidade de uso e acessibilidade (SCHOPFEL; ROCHE; 
HUBERT, 2015); o seu design espacial deve ser orientado para o cultivo de uma comunidade criativa (FUZI, 2015), como a inclusão de espaços abertos onde as pessoas podem ver umas às outras e espaços centrais onde elas podem interagir por acaso (ASSENZA, 2015); as regras e políticas de uso de espaços também podem influenciar a socialização, com regras de abertura e fechamento do ambiente ou políticas de registro, arquivamento e consulta de projetos concluídos por coworkers (SCHOPFEL; ROCHE; HUBERT, 2013).

Este modelo de espaço de socialização é contrastado pelo caso observado por Fuzi (2015) na comunidade de escritórios de coworking IndyCube Venture na região Sul do País de Gales. Os principais motivos dos usuários para a adesão eram: a) aproveitar a oportunidade que o espaço proporcionava de se encontrar com investidores e b) a infraestrutura de ponta do coworking (FUZI, 2015). A construção de uma comunidade não era uma prioridade na visão dos usuários, portanto, a colaboração, socialização e atividades comunitárias eram limitadas (FUZI, 2015). Ingressar neste coworking não seria vantajoso para usuários que desejassem aprimorar sua rede de contatos com seus pares e trocar experiências.

Os casos da biblioteca "The Edge" (BILANDZIC; FOTH, 2013) e do coworking IndyCube Venture (FUZI, 2015) permitem constatar que o conjunto dessas escolhas estratégicas criam espaços compartilhados diferenciados. Estas distinções são percebidas e avaliadas por usuários de espaços compartilhados e por usuários em potencial (SPINUZZI, 2012), atraindo coworkers com objetivos e expectativas diferentes. (FUZI, 2015). Spinuzzi (2012) apoia-se nestas diferenças em percepções e em objetivos entre usuários para classificar o coworking. $\mathrm{O}$ autor utilizou entrevistas com proprietários de coworking na região de Austin nos Estados Unidos, para entender como eles definem seu espaço e como eles explicam suas características e objetivos aos usuários. Isso o permitiu identificar três tipos de espaços de coworking:

- espaços de trabalho comunitário - o serviço é a oferta do espaço, com cada usuário possuindo funções e propósitos diferentes. Pode ser sem custos, como no caso do Space 12 - um espaço que visa servir a comunidade e pertence à igreja local. Apesar de trabalharem no mesmo espaço, não necessariamente se incentiva a colaboração e interação dos coworkers;

- escritórios (unoffice) - espaço de baixo custo para pessoas que desejam as amenidades e as interações que o ambiente de escritórios oferece. Discussões e a troca de conhecimentos são encorajadas, mas estabelecer uma comunidade é secundário. É baseado na ideia de que ao se aproximar pessoas talentosas e criativas, a colaboração ocorre naturalmente. Também 
procurado para a realização de eventos e encontros empresariais e como alternativa a cafés e outros espaços públicos.

- espaço de trabalho federativo (federated work space) - espaços que buscam fomentar o relacionamento formal e informal entre usuários a fim de facilitar a colaboração. Para os proprietários, o valor desses espaços é reunir uma rede de possíveis contratantes e parceiros de negócios sob um mesmo local, além de providenciar os mesmos benefícios que o modelo de escritórios.

As divergências de propósitos e expectativas entre os diversos atores envolvidos no contexto de coworking sugerem que deve haver uma escolha informada e deliberada de usuários de coworking para garantir que a cultura de trabalho do coworking esteja alinhada com suas expectativas e necessidades. Um caminho para alinhar cultura, expectativas e necessidades diferentes é a construção de visão, valores ou objetivos unificados entre usuários e entre usuários e hosts. Ao avaliar as lições que o coworking pode ensinar a bibliotecas universitárias, Schopfel, Roche e Hubert (2015) concluíram que é pertinente a criação de uma visão unificada entre usuários e hosts, por meio do compartilhamento de valores. Segundo Kubátová (2016), a ausência de uma visão ou objetivos compartilhados desincentivam coworkers a compartilharem seus conhecimentos. Capdevila (2015) aponta a relevância de se criar unidade entre as comunidades dentro do espaço de coworking, mas também com comunidades externas ao mesmo: nas comunidades externas encontram-se a próxima geração de usuários do coworking . Como instrumentos para formar e manter estas comunidades, Capdevila (2015) e Schopfel, Roche e Hubert (2015), mencionam a realização de eventos como palestras, debates e workshops.

Outra forma de construir visão, valores ou objetivos unificados é por meio da cocriação. Spinuzzi (2012) apresenta o processo de cocriação como forma de criar não apenas valores compartilhados, mas também para decidir sobre o propósito, a identidade e criar um significado comum para o espaço de coworking. Segundo Schopfel, Roche e Hubert (2015), o resultado da cocriação deve estar centrado nas necessidades da comunidade e não apenas nas necessidades dos proprietários como ocorre em modelos tradicionais de trabalho. Este alinhamento de valores, e outros aspectos intangíveis, também implica que o espaço deve facilitar o encontro com pessoas que já compartilham com essas visões e valores escolhidos e pessoas que auxiliem no processo de cocriação dos mesmos (ASSENZA, 2015; BILANDZIC; FOTH, 2013).

Para Spinuzzi (2012), na cocriação o propósito e a identidade do espaço são moldados de forma colaborativa entre diferentes usuários, e ao mesmo tempo, entre usuários e 
proprietários, por meio da troca contínua de experiências e de comunicação. Um exemplo empírico deste processo foi observado por Mileck e Padovani (2015) que entrevistaram um proprietário de coworking em São Paulo. O proprietário descreveu sua experiência como um processo de cocriação entre usuários do espaço, de tentativa e erro, situado entre as etapas de identificação e solução do problema, e que ocorre "sem compromisso com quantidade de pessoas, quantidade de encontros, duração dos encontros definidos e locais onde estes processos podem acontecer." (MILECK; PADOVANI, 2015, p. 78). Experiências semelhantes foram observadas por Spinuzzi (2012) e Fuzi (2015), a cocriação como um processo demorado e trabalhoso de transição para um espaço mais social e comunitário com valores compartilhados, que frequentemente exige de proprietários a conciliação de demandas e expectativas contraditórias de usuários.

O compartilhamento de visões e valores facilita a superação de obstáculos do processo de colaboração interorganizacional, ao formar uma mentalidade, conscientização ou vigilância capazes de lidar com as situações diversas que emergem de processos dinâmicos que envolvem a colaboração e o relacionamento entre pessoas de diferentes culturas organizacionais (LEUNG, 2013). Este dinamismo potencializado pelo compartilhamento de visões e valores permite, segundo Schopfel, Roche e Hubert (2015), que estes espaços de trabalho acompanhem as evoluções sociais e tecnológicas de seus usuários e das diferentes comunidades das quais eles fazem parte - os valores compartilhados renovam as dinâmicas sociais do trabalho tradicional, integram as diferentes redes de contatos dos usuários e incentivam a transferência de conhecimento e a inovação.

\subsection{A inovação do espaço de trabalho}

Um dos fatores explicativos para a proliferação de espaços de coworking é a sinergia com o avanço de tecnologias da informação e comunicação e com o trabalho a distância que elas possibilitaram (KUBÁTOVÁ, 2014). Há um interesse crescente pelo trabalho autônomo e o coworking, conforme ressalta o referido pesquisador, não apenas se mostra adequado a este modelo de trabalho, como também ajuda a mitigar duas de suas principais desvantagens: a compra das tecnologias, estruturas e serviços necessários para realizar seu trabalho e o isolamento do trabalhador individual. Como explica Kubátová (2014), uma das formas mais eficazes para autônomos adquirirem clientes é por meio de recomendações e o marketing bocaa-boca, logo o seu isolamento significa um empecilho na aquisição de novos clientes e uma 
renda irregular. O coworking permite a locação de um espaço com todos os equipamentos e serviços que o autônomo necessita e oferece a possibilidade do profissional conhecer novas pessoas e compartilhar conhecimentos.

O potencial de diferenciação do coworking na dimensão de oferta de espaço e equipamentos está limitado a questões como design, localização, qualidade da conexão de internet, etc. Por outro lado, o foco na dimensão de aspectos sociais encontrados no coworking tem a possibilidade de se diferenciar por ser um ambiente de inovação, tornando estes espaços mais atraentes como empreendimentos e para usuários que desejam inovar. Schopfel, Roche e Hubert (2015, p. 71, tradução nossa) associam aspectos sociais e a inovação ao descrever o coworking como: "Condutor da mudança, um mosaico de dinâmicas sociais e culturais, uma expressão e instigação da 'sabedoria das multidões' - os espaços de co-working estão na vanguarda do desenvolvimento social, um tipo de futurismo de escritório."

Como mencionado na seção 3.2, o coworking possui diversos significados e contextos, há situações nas quais o coworking não promove a interação entre pessoas ou a inovação. Alguns espaços de coworking observados em Barcelona (CAPDEVILA, 2015; PARRINO, 2015) e em Milão (PARRINO, 2015) resultaram apenas em escritórios compartilhados, enquanto outros se tornaram $h u b s$ inovadores e concentraram indivíduos com especialidades ou interesses comuns e específicos, em que a troca de conhecimentos com outros coworkers é um aspecto importante da experiência de compartilhamento do espaço de trabalho. Uma divisão semelhante - de espaços de coworking inovadores de alta intensidade social e aqueles menos inovadores e menos ativos socialmente - foi observada por Šviráková et al. (2015), em que um tipo de coworking visa oferecer apenas um baixo custo de escritório, no qual cada empreendimento fecha-se em um escritório e as interações com outros coworkers é pequena; e outro tipo de espaço, que possui diversos serviços como workshops e exibições, que atrai coworkers com mentalidade e propósitos mais comunitários e colaborativos.

Capdevila (2015) entende que há duas características de espaços de coworking que facilitam o surgimento destes hubs inovadores em relação aos ambientes tradicionais de trabalho: proximidade e abertura. A proximidade física beneficia a interação espontaneamente, ao facilitar a troca de conhecimento, as conversas informais e a criação de espaços e momentos também informais (SOERJOATMODJO et al., 2015). A abertura descreve a receptividade dos coworkers ao compartilhamento de recursos de trabalho e conhecimentos entre si (CAPDEVILA, 2015) e a ideias e pessoas pertencentes a comunidades externas (UDA, 2013). Para Bilandizic e Foth (2013) a interação social entre pessoas desconhecidas pode ser facilitada 
por circunstâncias sociais e espaciais. O coworking seria um espaço propício para promover a interação social, uma vez que a proximidade e abertura podem ser simultaneamente desenvolvidos, diferente do modelo tradicional de trabalho (UDA, 2013).

Mesmo que seja possível ter ambos, há indícios de que não há um relacionamento causal entre proximidade e abertura no contexto de espaços de coworking. A falta de interação observada em alguns espaços de coworking pode indicar que apenas a proximidade física e o compartilhamento do espaço físico não são suficientes para garantir vantagens da abertura como a colaboração, o networking ou o compartilhamento do conhecimento (FUZI, 2015; JYLHÄ et al., 2015; PARRINO, 2015) A pesquisa de Parrino (2015) encontrou casos em que os coworkers foram atraídos para o modelo de coworking com a expectativa de maior socialização, mas não obtiveram as vantagens do compartilhamento de conhecimentos porque os espaços não desenvolveram seus mecanismos de incentivo a interação. Para se obter as vantagens da abertura, ainda é necessário promover a interação, por exemplo, criando uma visão compartilhada ou uma estratégia de governança.

Em seu estudo teórico sobre a influência do espaço físico na criação de um ambiente de coworking que incentiva a criatividade e produtividade, Assenza (2015) utiliza uma definição mais ampla de espaço físico que inclui as estruturas organizacionais de governança. Segundo o pesquisador, em organizações tradicionais de trabalho, estruturas de governança como hierarquia e a forma como as equipes interagem umas com as outras são decididos de acordo com uma estratégia organizacional específica. Em espaços de coworking, a estratégia de governança é ser atraente para empreendedores e outros usuários que se sintam confortáveis com um espaço colaborativo e criativo e permaneçam como membros. Ao contrário da aproximação física entre atores diferenciados que ocorre naturalmente em espaços de coworking, a abertura da organização a atores externos, deve ser promovida ativamente para se criar um espaço colaborativo.

A possibilidade de que a colaboração e a interação não são características latentes ao compartilhamento do espaço físico possui implicações concretas. Os escritórios de coworking classificados como "Unoffice" na pesquisa de Spinuzzi (2012) são estruturados a partir da suposição dos proprietários de que a colaboração e a interação social vão emergir apenas do compartilhamento do espaço. Por sua vez, espaços classificados por Spinuzzi (2012) como "Federated workspaces" possuem a atitude de incentivar não apenas a interação casual, mas também a colaboração formal e relações de trabalho entre organizações, como contratos de negócios e indicações a clientes potenciais. 
Diversos autores concluem que a interação não ocorre naturalmente apenas com a proximidade ou colocação, e que promover a interação em coworking é uma decisão administrativa de hosts (LEUNG, 2013; UDA, 2013; ASSENZA, 2015; FUZI, 2015; SCHOPFEL; ROCHE; HUBERT, 2015; KUBÁTOVÁ, 2016). Essa interação pode ocorrer no contexto de participação de eventos: os eventos geralmente são organizados pelos funcionários dos espaços de coworking ou por interesse de usuários do espaço, eles permitem que usuários ofereçam conselhos e apoio uns aos outros, e assim, promovem a confraternização e o compartilhamento do conhecimento (CAPDEVILA, 2015). Outros exemplos concretos de interação formal que ocorrem em coworking, identificados por Soerjoatmodjo et al. (2015), são eventos de confraternização "speed networking”, em que dois coworkers conversam por alguns minutos e trocam de parceiros até que todos tenham tido a oportunidade de interagirem, e um mural no qual coworkers podem postar seus cartões de negócios, funcionando como um repositório das capacitações de todos os membros do espaço de coworking.

No coworking a motivação de usuários para interagirem é intrínseca (CAPDEVILA, 2015; KUBÁTOVÁ, 2016; POTTS; WATERS-LYNCH, 2016), logo o objetivo do gestor deve ser incentivar e permitir a expressão dessas motivações. Segundo Gandini (2015), as organizações em coworking estão sempre em um estado fluído e ambíguo entre a colaboração (para atingir objetivos comuns), cooperação (que amplia sua capacidade de trabalho) e competição por contratos de serviços ou produção, cabendo a seus gestores o desafio de interpretar esta ambiguidade.

\subsection{Configurações de trabalho em espaços de coworking}

A quarta categoria emergente da análise dos dados refere-se às configurações possíveis e suas influências sobre o trabalho em espaços de coworking. Como mencionado anteriormente, há configurações que resultaram apenas em escritórios compartilhados destinados a oferecer uma redução de custos em comparação com escritórios tradicionais. Também há casos em que se tornam hubs de inovação, também descritos como "espaços inovadores de alto desempenho" (CAPDEVILA, 2015) ou espaços mais comunitários e colaborativos (ŠVIRÁKOVÁ et. al., 2015).

A estratégia de hub especializado visa concentrar conhecimentos específicos semelhantes e que tenham sinergia entre si dentro de um mesmo espaço a fim de melhorar os produtos e serviços dos coworkers. A presença de afinidades e sinergias entre usuários que 
colaboram em espaços altamente inovadores, facilita a formação de um senso de comunidade entre usuários e incentiva o compartilhamento de conhecimentos técnicos e experiências. $\mathrm{O}$ objetivo é de que o espaço altamente inovador seja uma autoridade local nos assuntos em que o coworking se especializa (CAPDEVILA, 2015).

Outra configuração, descrita por Spinuzzi (2012), é a denominada "bons parceiros". Esta estrutura descreve a colaboração de diversos especialistas ou organizações, com diversas capacidades, dentro do espaço de coworking a fim de resolver a demanda de um cliente (Figura 3). Para Soerjoatmodjo et al. (2015) as colaborações entre coworkers visam o compartilhamento de conhecimento tácito acumulado pela experiência profissional dos coworkers. São trocados conhecimentos como a expertise de negócios, capacidades de gestão de projetos, regras, regulamentações e procedimentos (por exemplo, como registrar propriedade intelectual ou declarar impostos), insights de negócios (como oportunidades de empreendedorismo) e soluções de negócio. Ao colaborar, é possível completar projetos de escopo mais amplo, ou de prazo mais curto, do que se o coworker trabalhasse individualmente (SPINUZZI, 2012).

Figura 3 - Configuração de trabalho "bons parceiros" em coworking

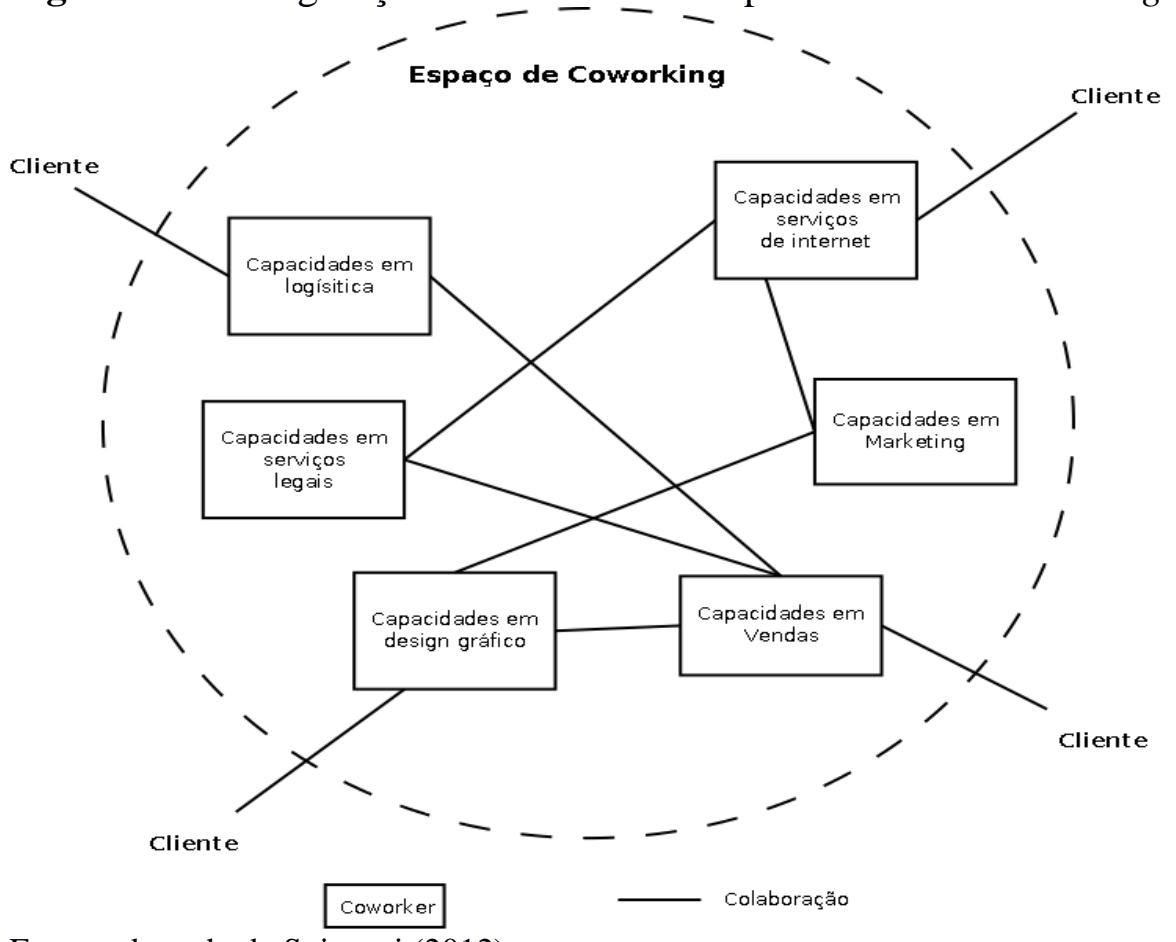

Fonte: adaptado de Spinuzzi (2012).

Na Figura 3, o "Cliente" representa um problema em comum que diversos coworkers colaboram para solucionar. O modelo consiste em um coworker que realiza um contrato de serviço com o cliente e colabora com outras equipes de trabalho dentro do coworking, que possuem as capacidades necessárias para solucionar o problema (SPINUZZI, 2012). As 
organizações colaboram comportando-se como uma rede organizacional, alterando o número de associados de cada organização de acordo com a necessidade do serviço prestado, assim como redes de freelancers (GANDINI, 2015). Estas redes possibilitam também a união de microempresas coworkers sob uma mesma identidade de marca para aumentar o reconhecimento pelo mercado (GANDINI, 2015); processo que é logisticamente mais simples quando ocorre em espaços de coworking. O objetivo desta estratégia é criar um espaço em que é possível encontrar soluções para a variedade de problemas que as comunidades venham a enfrentar (SCHOPFEL; ROCHE; HUBERT, 2015; ŠVIRÁKOVÁ et al., 2015).

Em ambas as configurações de trabalho em coworking de hubs especializados, em que se trabalha em projetos diferentes de uma mesma área, ou como "bons parceiros", em que diferentes áreas trabalham em um mesmo projeto a colaboração por projetos foi identificada como uma das principais interações entre coworkers (CAPDEVILA, 2015); ao colaborar é possível aproveitar-se da diversidade de especialidades acessíveis em espaços de coworking para aumentar a variedade, quantidade ou qualidade dos produtos e serviços que o empreendimento de um coworker oferece. Essa atuação conjunta de equipes de trabalho é momentânea e transitória, terminando com a resolução do problema (SPINUZZI, 2012). Quando equipes diferentes decidem se integrarem a fim de colaborarem, pode ser necessário um período de adaptação para que as pessoas construam relações de trabalho (LEUNG, 2013). A pesquisa de Leung (2013) revelou que durante estes períodos de adaptação, o papel de gestores em coordenar para além de suas fronteiras organizacionais foi significativo - ou até mesmo determinante - na finalização de projetos dentro dos prazos estipulados.

Deve-se evidenciar que a colaboração em contextos descentralizados, como os espaços de coworking, não deve ocorrer de modo igual a uma organização tradicional, com gestores realizando a seleção de equipes ou projetos. No coworking a motivação de usuários para colaborarem é intrínseca (CAPDEVILA, 2014), logo a função do gestor é incentivar e permitir a expressão dessas motivações de coworkers. É importante que hosts de coworking atuem como facilitadores da colaboração interorganizacional (FUZI, 2015). Porém, esta atuação é dificultada pela quantidade de tempo que demanda. A atuação como facilitador pode exigir interações diárias e entrevistas detalhadas com coworkers a fim de identificar suas necessidades atuais e prever suas necessidades futuras (SOERJOATMODJO et al., 2015). Para Bilandzic e Foth (2013) e Capdevila (2014) a atuação como facilitador significa o desenvolvimento dos fatores que condicionam a ocorrência da colaboração, como a criação de visões compartilhadas. Entre as visões compartilhadas utilizadas para promover a criatividade, inovação e colaboração 
estão: a valorização da liberdade e autonomia dos funcionários; a criação de um ambiente de confiança e transparência; a criação de valores compartilhados; e o acionamento da rede de contatos dos seus funcionários com pessoas externas à organização que podem contribuir na solução de problemas (CARVALHAL, MUZZO, 2015).

Enquanto a relação de trabalho baseada em projetos é temporária e pode ser frustrante (UDA, 2013), o relacionamento interpessoal criado e fortalecido entre coworkers durante a colaboração pode ser duradouro (CAPDEVILA, 2014). O trabalho colaborativo por projetos forma laços formais e informais entre as organizações parceiras que perduram ao longo do tempo. Capdevila (2014) observou que estas atividades colaborativas de coworking facilitam o surgimento de comunidades internas que interagem quase diariamente nos espaços. A colaboração facilita e agiliza futuras colaborações ao criar relações de confiança entre coworkers e contribui para o desenvolvimento de uma comunidade maior que interage de forma esporádica com a comunidade interna (CAPDEVILA, 2014). Ao unir comunidades internas e externas, o coworking se torna um hub local, reforçando a capacidade inovadora da região (CAPDEVILA, 2014).

As estratégias de hubs especializados e de "bons parceiros", estão fundamentadas na colaboração como forma de integrar o coworker com sua comunidade, ambas visam melhor agregar e compartilhar os conhecimentos, recursos, talentos e as redes de contatos fora do coworking de cada membro (SCHOPFEL; ROCHE; HUBERT, 2015). Bilandzic e Foth (2013) apresentam um modelo com quatro dimensões estratégicas em que a colaboração informal ocorre no contexto comunitário (Figura 4). 
Figura 4 - Modelo de colaboração como relacionamentos

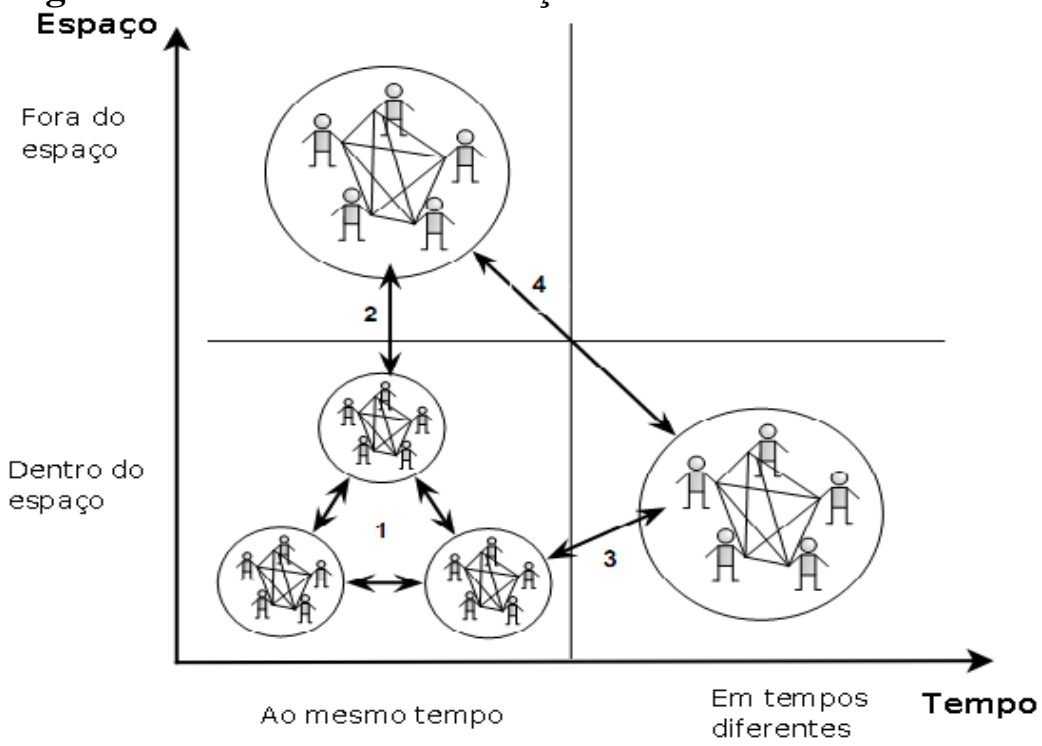

Fonte: Bilandzic e Foth (2013).

A relação 1 representada na Figura 4 é semelhante à apresentada na Figura 3 (SPINUZZI, 2012) e em espaços de coworking de alto desempenho (CAPDEVILA, 2015), em que diferentes empreendimentos colaboram dentro de um mesmo espaço de trabalho compartilhado. As relações 2 e 3, com pessoas de outros espaços e com pessoas que ocuparam o mesmo espaço no passado, podem ocorrer através de plataformas ou ferramentas de tecnologia da informação, como videoconferências e mensagens instantâneas, gravações de palestras ou workshops que ocorreram anteriormente naquele espaço compartilhado. O grupo ImpactHub, por exemplo, possui uma rede virtual global que permite que seus membros se comuniquem com qualquer ImpactHub do mundo e troquem suas experiências. Usuários da biblioteca The Edge utilizam a plataforma Meetup.com para se comunicar e organizar encontros entre pessoas de interesses comuns no espaço da biblioteca (BILANDZIC; FOTH, 2013). A relação 4, entre pessoas que ocupam outros espaços, pode ser explorada por dados de GPS deixados por usuários de aplicativos de celular, dados de redes sociais ou metadados. Outro tipo de informação útil a essa colaboração são dados pessoais de usuários destes outros espaços, como quais os seus interesses pessoais e profissionais, o que sabem fazer, quais as áreas atuam, em que projetos estão trabalhando e quais de seus projetos estão disponibilizados ao público (BILANDZIC; FOTH, 2013). Isso demanda que estes outros espaços registrem, organizem e disponibilizem estes dados para consultas. O espaço de trabalho compartilhado que deseja utilizá-los, deve agregar e divulgar estes dados entre os usuários do espaço, por meio de listas de e-mail, do seu site e pontos de divulgação interna, como quadros de anúncios; dessa forma 
o espaço estimula a comunicação e colaboração com comunidades externas. (BILANDZIC; FOTH, 2013).

Enquanto Capdevila (2015) destaca os projetos como a principal forma de interação entre coworkers, o modelo de Bilandzic e Foth (2013) (Figura 4) sugere que uma colaboração baseada apenas em tarefas ou projetos comuns pode ser limitada ou insuficiente. Para esses autores, a colaboração deve ser fundamentada em comunidades (internas e externas) e nos relacionamentos entre os colaboradores (em pessoa, digitalmente ou ao longo do tempo, com os registros de projetos passados). Schopfel, Roche e Hubert (2015) colaboram para a validação desta configuração ao apontar que o real valor do fenômeno de coworking está na formação de comunidades, nos encontros inesperados ou não intencionais, e nas conversas e relações informais entre coworkers. Embora um espaço que somente promove interações informais possua relações apenas esporádicas entre coworkers (PARRINO, 2015), a criação de laços comunitários também incentiva a criação de relações formais e recorrentes - como a relação cliente-fornecedor de dois coworkers, observada por Parrino (2015).

Para a formação de uma comunidade, é importante haver compatibilidade entre usuários, e entre usuários e proprietários no ambiente de coworking, de forma a incentivar a criação de confiança mútua. Para Spinuzzi (2012), a confiança possibilita o surgimento de objetivos comuns, os quais reforçam os laços comunitários. Para Soerjoatmodjo et al. (2015) e Maurer et al. (2015), a confiança mútua é uma condição, um pré-requisito, para a existência da colaboração. A literatura de coworking não estabelece uma relação direta clara entre características como colaboração, senso de comunidade, confiança mútua, compatibilidade entre coworkers e compartilhamento de valores e objetivos. Porém, diversos trabalhos afirmam que o desenvolvimento destas características é positivo para coworkers. Os resultados positivos destas estratégias de foco em comunidades geram possíveis questionamentos à efetividade da estratégia de especialização adotada por alguns proprietários de coworking (CAPDEVILA, 2015), e igualmente, para configurações tradicionais do trabalho, como as divisões setorial e funcional.

Šviráková et al. (2015) apontam que a sobrevivência financeira do espaço de coworking depende da capacidade do mesmo de oferecer valor agregado aos usuários. Em seu estudo sobre espaços de coworking na República Checa, Šviráková et al. (2015) notaram que a oferta integrada de serviços diversos como bares para a socialização, exibições de arte, lojas de materiais que coworkers utilizam e atividades de ensino (e.g. workshops, palestras, conferências), além da locação do espaço se traduzem em resultados financeiros sustentáveis, 
enquanto os espaços que focam suas estratégias de competição no baixo preço de locação do espaço encontram dificuldades financeiras com o passar dos anos. A renda adicional da diversificação de serviços oferece uma maior flexibilidade aos proprietários, ao permitir que o espaço contrate mais funcionários treinados na gestão de comunidades e da colaboração, a ocorrência de mais eventos e ao demandar um investimento inicial menor para a abertura do negócio (ŠVIRÁKOVÁ et al., 2015).

As considerações de Šviráková et al. (2015) e a colaboração que ocorre dentro e fora do espaço de trabalho compartilhado (Figura 4) indicam que o valor agregado que usuários desejam não se limita ao espaço e às ferramentas de trabalho, nem às relações de trabalho que podem ser encontradas em espaços compartilhados, mas inclui mecanismos de incentivo à formação de relacionamentos sociais, espaços de entretenimento, cultura e aprendizagem, acesso conveniente ao local, e outros motivos que não estão diretamente relacionados à redução de custos, ganhos de produtividade e eficiência ou aumento do lucro. Apenas a oferta do espaço físico também não oferece soluções para os indivíduos que trabalham em múltiplas localidades e plataformas (JYLHÄ et al., 2015; SPINUZZI, 2012). Logo é necessário um novo modelo de negócios para espaços como o coworking, um modelo cujos serviços suportam o trabalho em múltiplas localidades (não sendo limitados a um único espaço físico); para isso, é necessário idealizar novas propostas de valor e novas fontes de receitas para este modelo de coworking (JYLHÄ et al., 2015; POTTS; WATERS-LYNCH, 2016). Para Potts e Waters-Lynch (2016) haverá maior experimentação nas ofertas de coworking, com a combinação de novos serviços e a separação dos conjuntos de serviços existentes, até que proprietários sejam capazes de adaptar seus modelos de receita às preferências de seus clientes atuais e potenciais.

\section{CONCLUSÕES}

O objetivo desta pesquisa foi analisar os estudos sobre um conceito ainda recente e pouco explorado: o espaço de coworking. A pesquisa observou quatro categorias emergirem da análise dos dados: as origens e definições de coworking, as perspectivas de usuários (coworkers) e proprietários (hosts), a inovação do espaço de trabalho e as configurações de trabalho em espaços de coworking.

Em relação às origens e definições - categoria 1 -, constatou-se a possibilidade de analisar o coworking sob diversos contextos teóricos: como componente de cidades criativas, 
como atividade de consumo colaborativo, como espaço compartilhado de trabalho ou como forma de trabalho divergente das tradicionais. Observou-se também que não há um modelo único para a prática. Há casos em que o coworking é apenas um serviço que o ambiente oferece e não sua atividade principal. Foi possível reconhecer que o coworking tem potencial para servir a um nicho específico de usuários cujas demandas não estão sendo atendidas por outras modalidades de espaço de trabalho. Autores como Uda (2013), Gandini (2015) e Capdevila (2015) identificaram que os trade-offs de ambientes tradicionais de trabalho associados à proximidade ou abertura e à interação ou diversidade podem ser superados pelo trabalho em espaços de coworking.

Quanto às perspectivas de usuários (coworkers) e proprietários (hosts) - categoria 2 foram identificadas ambiguidades sobre o propósito do fenômeno coworking, tanto entre os usuários quanto entre usuários e proprietários. Como consequência, pôde-se encontrar expectativas e objetivos divergentes. Dessa forma, identificaram-se espaços com propostas de valor diferentes, como: um que o usuário é livre para utilizar segundo seus objetivos; um espaço que permite economias de custos; e um espaço que promove a construção de uma comunidade. A pesquisa identificou casos em que o alinhamento de objetivos entre usuários e proprietários trouxe resultados positivos em desempenho e finanças, assim como casos em que a dissonância interferiu no trabalho de usuários. Constatou-se que o papel dos proprietários tem relevância para o alinhamento e que um mecanismo adequado para essa tarefa é o compartilhamento de valores entre os usuários, bem como entre usuários e proprietários (SCHOPFEL; ROCHE; HUBERT, 2015).

A inovação do espaço de trabalho - categoria 3 - trata de como ocorre o trabalho em espaços de coworking e como ele difere de ambientes tradicionais. Foram observados fatores condicionantes e de incentivo à colaboração e inovação, presentes em espaços de coworking. Alguns espaços se tornam inovadores, enquanto outros demonstram pouca interação entre coworkers (CAPDEVILA, 2015). Identificou-se que tal diferença pode ser, em parte, explicada por fatores como o grau de proximidade física entre usuários e o grau de abertura a ideias e a conhecimentos externos ao espaço (UDA, 2013; CAPDEVILA, 2015).

Diversos autores concordam que, enquanto a proximidade pode ser determinada por fatores estruturais, a abertura pode ser incentivada pela ação gerencial dos hosts de espaços de coworking (LEUNG, 2013; UDA, 2013; ASSENZA, 2015; FUZI, 2015; PARRINO, 2015; SCHOPFEL; ROCHE; HUBERT, 2015). Em outras palavras, para atingir o potencial inovador, é necessário que os hosts participem, ou mesmo, liderem um processo de construção de valores 
compartilhados dentro do espaço. Diferente de formas de trabalho tradicional, a colaboração entre coworkers não pode ser forçada com uma ordem legitimada pelo poder hierárquico. A motivação para a colaboração é intrínseca (CAPDEVLA, 2015), logo a gestão de hosts tem o papel de influenciar - não comandar - e ocorre por meio de técnicas como a construção de valores compartilhados (CARVALHAL; MUZZO, 2015). Tais valores são específicos para cada contexto de trabalho (LEUNG, 2013). De forma genérica, para promover ambientes de inovação, os valores compartilhados devem estar associados à formação de uma comunidade interna, ao compartilhamento de conhecimentos e recursos, à promoção da transparência, da autonomia e da criatividade, à construção da confiança, da solidariedade e da colaboração entre coworkers, bem como à abertura a conhecimentos novos, de diferentes fontes (LEUNG, 2013; UDA, 2013; ASSENZA, 2015; CAPDEVILA, 2015; CARVALHAL; MUZZO, 2015; SCHOPFEL; ROCHE; HUBERT, 2015).

Em relação às configurações de trabalho em espaços de coworking - categoria 4 -, foi constatado que a principal forma de colaboração é a realização de projetos compartilhados entre coworkers (SPINUZZI, 2012; CAPDEVILA, 2015), porém essa visão pode ser limitada (BILANDZIC; FOTH, 2013). Alguns autores enfatizam a importância da colaboração informal para espaços de coworking, sugerindo que a construção de uma comunidade que colabora é uma proposta de valor mais próxima daquela demandada pelo trabalhador atual (BILANDZIC; FOTH, 2013; SCHOPFEL; ROCHE; HUBERT, 2015; SPINUZZI, 2012; ŠVIRÁKOVÁ et al., 2015). A estratégia de focar em construir uma comunidade pode ser a escolha mais financeiramente atraente para proprietários e apresenta a possibilidade de atender uma maior quantidade de necessidades de usuários. Necessidades como por exemplo: o pertencimento a uma comunidade, um ponto de encontro para hobbistas, um espaço para o aprimoramento pessoal ou profissional, o maior controle sobre o local, tempo e condições de trabalho.

A pesquisa realizada contribuiu de três formas para o estudo de espaços de coworking. A primeira foi o mapeamento da literatura internacional e nacional de coworking, em um momento no qual havia apenas uma revisão da literatura sobre o tema, restrita a trabalhos internacionais. A segunda contribuição foi a identificação de categorias emergentes que retratam os escritos sobre o fenômeno (Quadro 2) e as conclusões advindas da análise interpretativa dos conteúdos referentes a essas categorias (seção 3 do artigo). A terceira contribuição foi a identificação de oportunidades para pesquisas futuras.

Uma destas decorre da lacuna de estudos que exploram relacionamentos entre características potencialmente presentes em espaços de coworking, como colaboração, senso de 
comunidade, confiança mútua, compatibilidade entre coworkers e compartilhamento de valores e objetivos. Ainda que diversos trabalhos estejam direcionados ao estudo de algumas dessas características individualmente no contexto de coworking, uma sugestão de estudo futuro é o esclarecimento de como elas se relacionam ou como se combinam para impactar organizações usuárias e coworkers individuais.

Algumas das publicações identificadas tratam de aspectos do coworking que não estão associados somente à vida profissional do coworker. Por exemplo, no estudo de Spinuzzi (2012), usuários justificam a escolha de seus espaços quer pela proximidade a creches ou bares e restaurantes, quer pela política de permitir cachorros no local. Esses aspectos indicam que o sucesso do coworking pode ser explicado por um movimento de mudança no estilo de vida desejado pela geração atual da força de trabalho, um estilo de vida balanceado, no qual as barreiras entre vida pessoal e profissional se tornam mais tênues. Se o coworking for capaz de contribuir para um maior balanço entre a vida pessoal e profissional, isso o tornará um fenômeno excepcional. Portanto, uma sugestão de estudos futuros é analisar se o coworking apresenta potencial para facilitar o balanço entre a vida pessoal e profissional e de que maneiras isso pode ocorrer.

Outra oportunidade de estudo remete à influência da configuração espacial de espaços de coworking no trabalho colaborativo, uma vez que a maioria dos trabalhos identificados focam em aspectos sociais. Um tema a ser investigado, relevante a proprietários e hosts, é como identificar e apresentar a proposta de valor de espaços de coworking específicos e como melhorar a oferta do conjunto de serviços entendido como coworking. Tais considerações implicam diferentes modelos de negócios e de rentabilidade, daí poderem decidir a viabilidade e longevidade do espaço. Por fim, sugerem-se novas pesquisas em espaços de coworking localizados no Brasil. Como mencionado, cada espaço do tipo pode desenvolver uma comunidade e cultura próprias, informadas por seus respectivos contextos regionais e nacionais. A propósito, ainda não se estudou a influência da cultura brasileira na prática do coworking.

Uma limitação desta pesquisa foi a escolha exclusiva dos parâmetros "coworking” ou “co-working” para o mapeamento dos trabalhos publicados, não utilizando conceitos anteriores que possam ajudar a explicar o fenômeno, como empreendedorismo, consumo colaborativo, cidades criativas e espaços compartilhados. Todos estes são tratados em diversos trabalhos identificados nesta pesquisa. É importante notar a consideração de Gandini (2015) sobre o risco de a literatura de coworking ser excessivamente otimista devido à novidade do fenômeno, que 
deve ser visto como mais uma modalidade de trabalho, com vantagens e desvantagens, sendo efetivo ou ineficaz dependendo de como é constituído e gerenciado. 


\section{REFERÊNCIAS}

ASSENZA, Pauline. If You Build It Will They Come? The Influence of Spatial Configuration on Social and Cognitive Functioning and Knowledge Spillover in Entrepreneurial Co-Working and Hacker Spaces. Journal of Management Policy and Practice, v. 16, n. 3, p. 35-48, 2015.

BARDIN, L. Análise de Conteúdo. Lisboa, Portugal: Edições 70, LDA, 2009.

BILANDZIC, Mark; FOTH, Marcus. Libraries as coworking spaces: Understanding user motivations and perceived barriers to social learning. Library Hi Tech, v. 31, n. 2, p. 254-273, 2013.

CAPDEVILA, Ignasi. Typologies of Localized Spaces of Collaborative Innovation. 2013. Disponível em: <https://ssrn.com/abstract=2414402> ou Acesso em: 14 ago. 2016.

Different Inter-Organizational Collaboration Approaches in Coworking Spaces in Barcelona. 2014. Disponível em: < https://ssrn.com/abstract=2502816> ou <http://dx.doi.org/10.2139/ssrn.2502816>. Acesso em: 14 ago. 2016. Doi: $10.2139 /$ ssrn. 2414402 .

Co-working spaces and the localised dynamics of innovation in Barcelona. International Journal of Innovation Management (IJIM), v. 19, n. 03, p. 1 -28, 2015.

CARVALHAL, Felipe; MUZZIO, Henrique. Economia criativa e liderança criativa: uma associação (im)possível?. REAd: Rev. eletrôn. adm., Porto Alegre, v. 21, n. 3, p. 659-688, set/dez, 2015. Disponível em: < http://www.scielo.br/pdf/read/v21n3/1413-2311-read-21-0300659.pdf> Acesso em: 14 ago. 2016. Doi: 10.1590/1413-2311.0032015.54929.

COWORKING BRASIL. Censo Coworking Brasil 2017. Disponível em: <https://coworkingbrasil.org/censo/2017/>. Acesso em 01 mai. 2018.

DESKMAG. 2018 Global Coworking Survey. Disponível em: <https://www.dropbox.com/s/rjbmdo4wp4aeccx/2018\%20Complete\%20Coworking\%20Fore cast.pdf?dl=0>. Acesso em 01 mai. 2018.

DOS SANTOS, Claudia Maria Neme. Coworking: contribuições de um modelo de consumo colaborativo e da arquitetura corporativa para o gerenciamento das cidades. Revista Nacional de Gerenciamento de Cidades, v. 2, n. 12, p. 84-95, 2014. 
DRISKO, James W., MASCHI, Tina. Content analysis. Oxford; New York: Oxford University Press, 2016.

EISENHARDT, K. M. Building Theories from Case Study Research. Academy of Management Review, v. 14, n. 4, p. 532-550, 1989.

FUZI, Anita. Co-working spaces for promoting entrepreneurship in sparse regions: the case of South Wales. Regional Studies, Regional Science, v. 2, n. 1, p. 462-469, 2015.

GANDINI, Alessandro. The rise of coworking spaces: A literature review. Ephemera, v. 15, n. 1, p. 193-205, 2015.

GERBER, J.; MIRANDA, R.; BORNIA, A.; FREIRES, F. Organização de referenciais teóricos sobre diagnóstico para a previsão de demanda. GESTÃO.Org: Rev. Eletrôn. de gestão org., v. 11, n. 1, p. 160-185, jan./abr., 2013. Disponível em: $<$ http://www.spell.org.br/documentos/ver/11614/organizacao-de-referenciais-teoricos-sobrediagnostico-para-a-previsao-de-demanda/i/pt-br>. Acesso em 08 ago. 2016.

GODOY, A. S. Introdução à pesquisa qualitativa e suas possibilidades. Revista de Administração de Empresas, v. 35, n. 2, p. 57-63, mar./abr., 1995

JYLHÄ, Tuuli et al. Towards business potential of workplace services in Finland. Procedia Economics and Finance, v. 21, p. 518-523, 2015.

KOJO, Inka et al. Typologies for co-working spaces in Finland-what and how? Facilities, v. 34, n. 5/6, p. 302-313, 2016.

KUBÁTOVÁ, Jaroslava. The Cause and Impact of the Development of Coworking in the Current Knowledge Economy. In: EUROPEAN CONFERENCE ON KNOWLEDGE MANAGEMENT ECKM, 15., Sep. 2014, London. Proceedings... Kidmore End: Academic Conferences and Publishing International Limited, 2014. p. 571 - 577.

. Cultural Differences in Knowledge Sharing in Virtual Environment. In: EUROPEAN CONFERENCE ON KNOWLEDGE MANAGEMENT ECKM, 17., Sep. 2016, London. Proceedings... Kidmore End: Academic Conferences and Publishing International Limited, 2016. p. 513-519

LEUNG, Zeno CS. Boundary spanning in interorganizational collaboration. Administration in Social Work, v. 37, n. 5, p. 447-457, 2013. 
LIEBOWITZ, J.; BECKMAN, J. Knowledge organizations: what every manager should know. Nova York: St. Lucie, 1998.

MAURER, Angela Maria et al. Yes, we also can! O desenvolvimento de iniciativas de consumo colaborativo no Brasil. BASE: Revista de Administração e Contabilidade da Unisinos, v. 12, n. 1, p. 68-80, 2015.

MAZNEVSKI, M.; ATHANASSIOU, N. Bringing the Outside In: Learning and Knowledge Management Through External Networks. In: ICHIJO,K.; NONAKA, I. Knowledge creation and management: new challenges for managers. Nova York: Oxford University Press, Inc., 2007.p. 69-82.

MILECK, Luiz Henrique Strapasson; PADOVANI, Stephania. Cocriação no mercado: um estudo exploratório de processos criativos de empreendedores. Strategic Design Research Journal, v. 8, n. 2, p. 74-82, 2015.

NONAKA, I.; TAKEUCHI, H. Criação de conhecimento na empresa: como as empresas japonesas geram a dinâmica da inovação. Rio de Janeiro: Campus, 1997.

PARRINO, Lucia. Coworking: assessing the role of proximity in knowledge exchange. Knowledge Management Research \& Practice, v. 13, n. 3, p. 261-271, 2015.

POTTS, Jason; WATERS-LYNCH, Julian M. The Social Economy of Coworking Spaces: A Focal Point Model of Coordination. 2016. Disponível em: <https://ssrn.com/abstract=2770874>. Acesso em: 14 ago. 2016. Doi: 10.2139/ssrn.2770874.

PRATT, Andy C. Creative cities: the cultural industries and the creative class. Geografiska annaler: series B, human geography, v. 90, n. 2, p. 107-117, 2008.

ROHDEN, Simoni Fernanda et al. Consumo Colaborativo: Economia, Modismo ou Revolução? Desenvolve Revista de Gestão do Unilasalle, v. 4, n. 2, p. 09-24, 2015.

SCHOPFEL, Joachim; ROCHE, Julien; HUBERT, Gilles. Co-working and innovation: new concepts for academic libraries and learning centres. New Library World, v. 116, n. 1/2, p. 67-78, 2015.

SOERJOATMODJO, Gita Widya Laksmini, et al. Sharing Workspace, Sharing Knowledge: Knowledge Sharing Amongst Entrepreneurs in Jakarta Co-Working Spaces. In: INTERNATIONAL CONFERENCE ON INTELLECTUAL CAPITAL AND KNOWLEDGE 
MANAGEMENT AND ORGANISATIONAL LEARNING, 12., 2015. Proceedings... Kidmore End: Academic Conferences International Limited, 2015, p. 259-267.

SPINUZZI, Clay. Working alone together coworking as emergent collaborative activity. Journal of Business and Technical Communication, v. 26, n. 4, p. 399-441, 2012.

STRAUSS, A.; CORBIN, J. Basics of qualitative research: techniques and procedures for developing grounded theory. 2. ed. Thousand Oaks, California: Sage Publications, 1998.

ŠVIRÁKOVÁ, Eva et al. Culture managers education: system dynamics model of the coworking design centre. Procedia-Social and Behavioral Sciences, v. 174, p. 1684-1694, 2015.

UDA, Tadashi. What is Coworking? A Theoretical Study on the Concept of Coworking. 2013. Disponível em <https://ssrn.com/abstract=2937194> Acesso em: 14 ago. 2016. Doi: $10.2139 /$ ssrn.2937194. 